\title{
Finite element analysis of the residual thermal stresses on functionally gradated dental restorations
}

\author{
B. Henriques ${ }^{a, d, *}$, G. Miranda ${ }^{a}$, M. Gasik ${ }^{b}$, J.C.M. Souza ${ }^{a, e}$, R.M. Nascimento ${ }^{c}$, \\ F.S. Silva ${ }^{a}$ \\ ${ }^{a}$ CMEMS-UMinho, University of Minho, Campus de Azurém, 4800-058 Guimarães, Portugal \\ ${ }^{\mathrm{b}}$ Department of Materials Science and Engineering, School of Chemical Technology, Aalto University Foundation, \\ 00076 Aalto, Espoo, Finland \\ ${ }^{\mathrm{c} D e p a r t a m e n t}$ of Materials Engineering, Federal University of Rio Grande do Norte, 59072-970 Natal, RN, ;Brazil

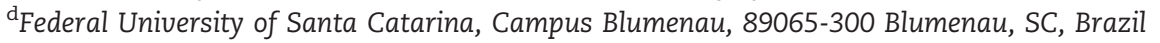 \\ ${ }^{\mathrm{e}}$ School of Dentistry (DODT), Post-Graduation Program in Dentistry (PPGO), Federal University of Santa Catarina, \\ Campus Trindade, 88040-900 Florianópolis, SC, Brazil
}

\section{A R T I C L E I N F O}

Article history:

Received 13 February 2015

Received in revised form

28 May 2015

Accepted 1 June 2015

Available online 19 June 2015

Keywords:

Dental restorations

Functionally gradated materials

Metal

Ceramic

\begin{abstract}
A B S T R A C T
The aim of this work was to study, using the finite element method (FEM), the distribution of thermal residual stresses arising in metal-ceramic dental restorations after cooling from the processing temperature. Three different interface configurations were studied: with conventional sharp transition; one with a 50\% metal-50\% ceramic interlayer; and one with a compositionally functionally gradated material (FGM) interlayer. The FE analysis was performed based on experimental data obtained from Dynamic Mechanical Analysis (DMA) and Dilatometry (DIL) studies of the monolithic materials and metal/ceramic composites.

Results have shown significant benefits of using the $50 \%$ metal-50\% ceramic interlayer and the FGM interlayer over the conventional sharp transition interface configuration in reduction of the thermal residual stress and improvement of stress profiles. Maximum stresses magnitudes were reduced by $10 \%$ for the crowns with $50 \%$ metal-50\% ceramic interlayer and by $20 \%$ with FGM interlayer. The reduction in stress magnitude and smoothness of the stress distribution profile due to the gradated architectures might explain the improved behavior of these novel dental restorative systems relative to the conventional one, demonstrated by in-vitro studies already reported in literature.
\end{abstract}

(c) 2015 Elsevier Ltd. All rights reserved.

\section{Introduction}

Dental restorations such as crowns and fixed partial dentures (FPD) are designed to restore functionality and esthetics to failed teeth. They are based on multi-material and multilayered systems, comprising a strong metallic or ceramic substructure veneered and esthetic dental porcelain that mimic the color of the remaining teeth. Failures of the restorative systems are undesired occurrences as they often imply money expenditure and discomfort to patients. Several studies have been conducted

\footnotetext{
*Corresponding author at: CMEMS-UMinho, University of Minho, Campus de Azurém, 4800-058 Guimarães, Portugal. Tel.: +351 253 510220; fax: +351253516007.

E-mail address: brunohenriques@dem.uminho.pt (B. Henriques).
} 
to understand and determine the failure mechanisms of the metal-ceramic and all-ceramic restorative systems (Yesil et al., 2009; Özcan, 2003; Anusavice, 2012; Swain, 2009, Arman et al., 2009; Zhang et al., 2010, 2012). Failures during the fabrication process related to thermal residual stresses arising from cooling after high temperature processing, and problems due to poor chemical compatibility have been pointed as the main causes for such events (Fischer et al. 2009). The cooling rates, the mismatching thermomechanical properties of materials and the geometry of specimens can greatly impact the transient residual stresses in metal-ceramic and all-ceramic restorations (Zhang et al. 2010; Asaoka and Tesk, 1990; Taskonak et al., 2005, 2008; DeHoff et al., 2008). Moreover, the thermal incompatibility between the materials to join can result in high stresses in regions close to free surface and near the interface, which can lead to either cracking of the ceramic or joints having poor strength (DeHoff et al. 2008; Ravichandran, 1995).

Functionally Gradated Materials (FGMs) can be an answer to the thermal stress problems (Gasik, 1998, Gasik et al., 2005) consisting in a gradual change in the volume fractions of constituents from one location to the other in a component. The FGMs were first applied in minimizing thermal stresses and increasing thermal shock resistance of blades in gas turbine engines, with great success (Ravichandran, 1995; Chi and Chung, 2003). The philosophy was rapidly adapted by engineers to other fields of activity such as optics, nuclear energy, engineering, electronics, biomaterials, among others.

The employment of FGM to restorative dentistry is rather novel. Several studies were carried out involving metalceramic and all-ceramic dental restorative systems, aiming for the enhancement of the overall clinical performance. Gradated restorations have been shown to display improved properties relative to conventional ones, especially concerning to higher resistance to contact and sliding (Suresh, 2001); higher adhesion of porcelain to the substructure (metal or ceramic) (Henriques et al., 2011, 2012a, 2012b; Zhang and Kim, 2009); improved esthetical properties and improved fatigue performance (Henriques et al. 2012b).

In this study, the finite element analysis (FEA) was used to investigate the influence of the presence of a $50 \%$ metal$50 \%$ ceramic composite interlayer and a gradated interlayer at interface of a metal-ceramic dental crown on the post processing thermal residual stresses. Therefore, two different classes of gradation were studied, one consisting in a one-step transition only (interlayer with the composition of $50 \%$ metal-50\% ceramic), and the other consisting in multiple layers of different compositions (each layer with constant composition), both performing a compositional discrete transition between metal and ceramic as a function of distance. The results obtained with these new interface configurations were compared with the conventional sharp transition system. The mechanical and thermal properties of the materials used in this study were experimentally determined through the production and testing of homogeneous specimens of several compositions. The elastic and thermal experimental data were afterwards modeled and uploaded in the materials properties database of the finite element method software.

\section{Materials and methods}

\subsection{Experimental determination of the elastic modulus and the coefficient of thermal expansion}

In this study a CoCrMo alloy (Nobil 4000, Nobilmetal, Villafranca d'Asti, Italy) and a dental porcelain (Ceramco3, Dentsply, York, USA) (batch number: 08004925) were used. The chemical compositions of the metallic and ceramic particles are presented in Table 1 and Table 2, respectively. The micrographs of CoCrMo and porcelain powders show angular shapes and spherical shapes, respectively (Fig. 1). The CoCrMo powders display a broad size distribution: $D_{10}=4.44 \mu \mathrm{m} ; \quad D_{50}=8.27 \mu \mathrm{m} \quad$ and $D_{90}=12.76 \mu \mathrm{m}$.

The manufacturing of the metal-ceramic composite specimens comprised the following steps: several powder mixtures with different metal/porcelain volume fractions were produced. After weighting, the powders mixtures were blended in a rotary machine at $40 \mathrm{rpm}$ during $10 \mathrm{~min}$. The following mixtures were produced (vol\%): pure porcelain (with $0 \%$ metal) and compositions with $20 \%$ metal, $40 \%, 60 \%, 80 \%$ and $100 \%$ metal, marked further as "nnM" where nn stays for the percentage of metal phase. Afterwards, the powder mixtures were hot pressed in a graphite die (Fig. 2). The hot pressing sequence comprised the following steps: first, the cavity of the graphite die was veneered with $\mathrm{ZrO}_{2}$ paint to prevent carbon diffusion to specimens. Then the metal-ceramic powder mixture was inserted into the cavity. The hot pressing was performed under vacuum $\left(\sim 10^{-2} \mathrm{mBar}\right)$ at a temperature of $970{ }^{\circ} \mathrm{C}$ and a constant pressure of $\sim 20 \mathrm{MPa}$. The selected heat rate was $70{ }^{\circ} \mathrm{C} / \mathrm{min}$ and after a 2 min stage at $970{ }^{\circ} \mathrm{C}$ the induction heating furnace was shut down. Specimens cooled down to room temperature inside the hot pressing equipment.

Two types of specimens' geometries were processed, rectangular and cylindrical. The dimensions of the rectangular samples used for flexural tests were $36 \times 6 \times 2.5 \mathrm{~mm}$, while those of the cylindrical samples used for shear tests were $\varnothing 4 \times 4 \mathrm{~mm}$.

The measurements of Young's moduli (YM) of all materials were obtained by the means of Dynamic Mechanical Analysis (DMA 242C, Netzsch Gerätebau GmbH, Germany) using a three-point bending sample holder. The coefficient of thermal expansion (CTE) of composites and the monolithic materials was also assessed using dilatometry (DIL 402C, Netzsch Gerätebau GmbH, Germany). Both properties were measured through a range of temperatures starting in $100^{\circ} \mathrm{C}$ up to $500^{\circ} \mathrm{C}$. It was estimated that materials properties at $100{ }^{\circ} \mathrm{C}$ did not differ significantly from properties at room temperature. Poisson's ratio was fixed to be the following for the different materials: metal (0.25); porcelain (0.2); $50 \mathrm{M}$ composite interlayer (0.23). For the gradated transition Poisson's ratio was approximated varying linearly from that of metal to that of porcelain. Data were post-processed with the

Table 1 - Base alloy composition (wt\%) (according to manufacturer).

\begin{tabular}{lllll} 
Co & Cr & Mo & Si & Impurities \\
\hline 62 & 31 & 4 & 2.2 & Mn, Fe, W \\
\hline
\end{tabular}




\section{Table 2 - Porcelain chemical composition (wt\%).}

\begin{tabular}{ccccccccc}
$\mathrm{SiO}_{2}$ & $\mathrm{Al}_{2} \mathrm{O}_{3}$ & $\mathrm{~K}_{2} \mathrm{O}$ & $\mathrm{SnO}_{2}$ & $\mathrm{ZrO}_{2}$ & $\mathrm{CaO}$ & $\mathrm{P}_{2} \mathrm{O}_{5}$ & $\mathrm{Na}_{2} \mathrm{O}$ & $\mathrm{Impurities}$ \\
\hline 41.3 & 14.5 & 14.0 & 11.9 & 5.8 & 4.1 & 4.1 & 3.0 & $\mathrm{MgO}_{2} \mathrm{SO}_{3}, \mathrm{ZnO}_{\mathrm{Cr}} \mathrm{Cr}_{2} \mathrm{O}_{3}, \mathrm{Fe}_{2} \mathrm{O}_{3}, \mathrm{CuO}_{,} \mathrm{Rb}_{2} \mathrm{O}$ \\
\hline
\end{tabular}
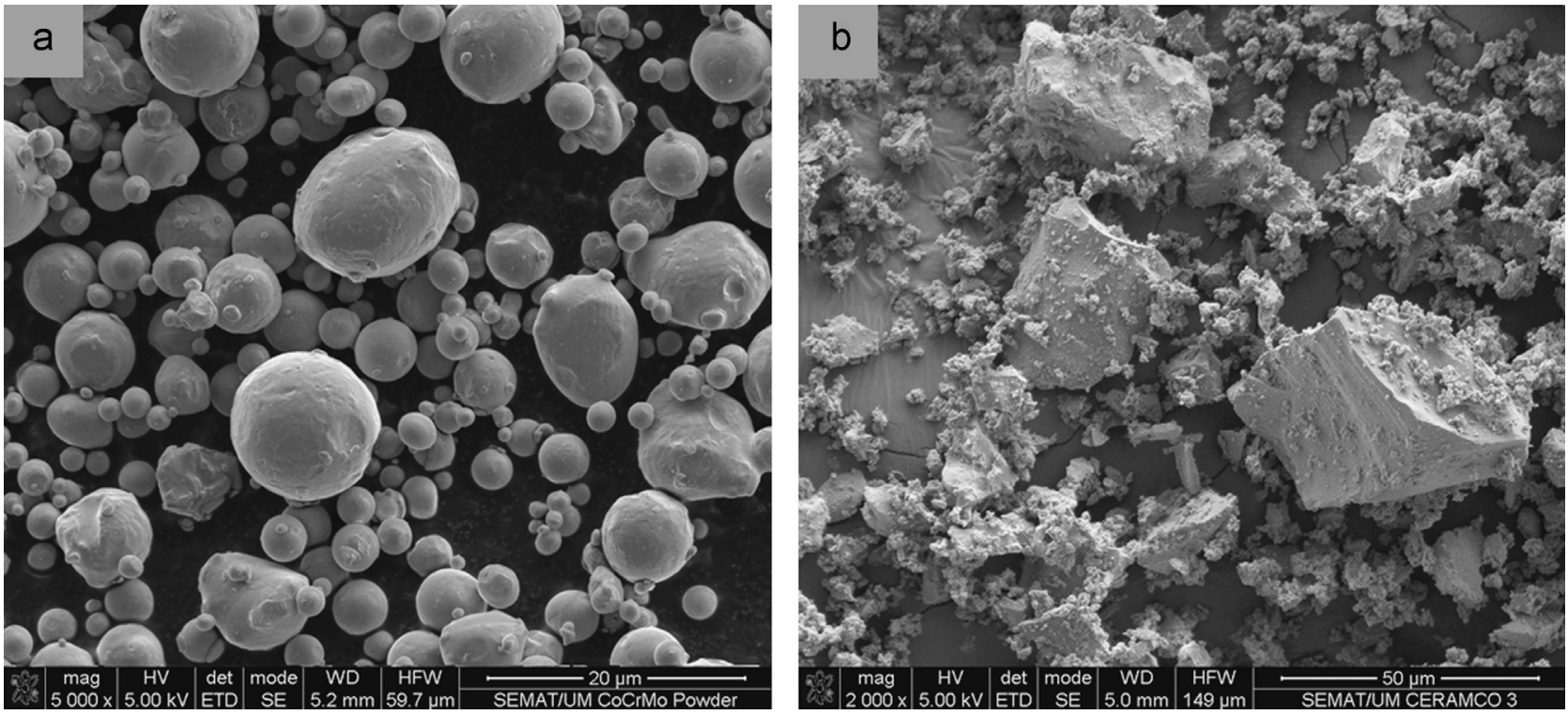

Fig. 1 - Micrograph of the metal and ceramic powders: (A) CoCrMo particles; (B) porcelain powders.
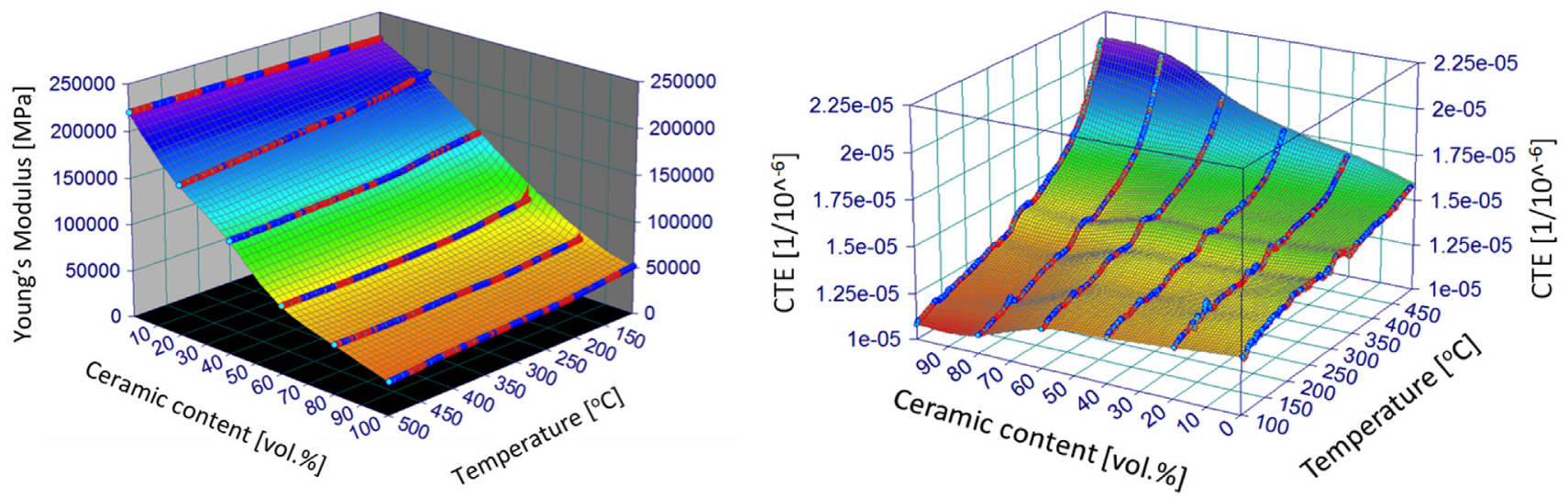

Fig. 2 - Plot of the mechanical (Young's Modulus) and thermal (CTE) properties of composite materials against temperature variation.

software TableCurve3D (Systat Software, Inc., San Jose, California, USA) to produce functional equations and the surface plots of Young's moduli (YM) and the coefficient of thermal expansion, which are shown in Fig. 2A and B, respectively. The YM variation is given by the Eq. (1) and the thermal expansion coefficient is given by the Eq. (2). The values of the constants for both equations are shown in Table 3.

$\mathrm{YM}=\mathrm{A}+\mathrm{Bx}+\mathrm{Cy}+\mathrm{Dy^{2 }}+\mathrm{Cy} \mathrm{y}^{3}$

$\mathrm{CTE}=\mathrm{A}+\mathrm{Bx}+\mathrm{Cy}+\mathrm{Dx} x^{2}+\mathrm{Ey}^{2}+\mathrm{Fxy}$

where $\mathrm{x}$ is the temperature (degrees Celsius) and $\mathrm{y}$ is the ceramic content in the composite (vol\%).
Table 3 - Constants used in Eqs. (1) and (2).

\begin{tabular}{lll} 
& YM & CTE \\
\hline A & 234750.25 & $1.53 \mathrm{E}-05$ \\
B & -50.80 & $-1.30 \mathrm{E}-08$ \\
C & -1865.11 & $-5.00 \mathrm{E}-08$ \\
D & -19.68 & $3.14 \mathrm{E}-11$ \\
E & 0.21 & $-3.08 \mathrm{E}-11$ \\
F & & $1.55 \mathrm{E}-10$ \\
\hline
\end{tabular}

\subsection{Finite element analysis}

The thermal residual stress analysis after the cooling process was performed for three types of crown designs: sharp 
transition; 50M composite interlayer (thickness $=500 \mu \mathrm{m}$ ); and compositionally gradated transition - FGM (total thickness $=$ $500 \mu \mathrm{m})$ through 9 discrete intermediate layers (individual thickness $=55 \mu \mathrm{m}$ ). The selection of number of layers in the FGM configuration was arbitrary but chosen to illustrate the relative levels of residual stresses. In this work, a 3D molar tooth model was used (Fig. 3). The FEA was conducted using the commercial finite element software COMSOL Multiphysics 4.3a (Comsol Inc, Los Angeles, USA) adapting triangular elements. In order to simplify the study, the 3D computational model of the crow was sectioned to a 2D-axisymmetric model (Zhang et al., 2010, 2012) (Fig. 3).

The computational procedure consisted in cooling the model from a temperature of $500{ }^{\circ} \mathrm{C}$ to $100{ }^{\circ} \mathrm{C}$, during $1000 \mathrm{~s}$ in increments of $100 \mathrm{~s}$, i.e. with a constant cooling rate of $0.25 \mathrm{~K} / \mathrm{s}$. The thermal residual stresses, in its five components (radial, vertical, shear and hoop), were taken for each model after the cooling time elapsed. The convergence analysis was performed in order to examine the sensitivity of the results to the size of the mesh. Differences in maximum principle stresses were found to be lower than $3 \%$ for consecutive mesh refinements. The evolution of the coefficient of thermal expansion and Young's modulus for the different metalceramic interface designs used in this study are schematically shown in Fig. 4. The properties of materials presented are based on experimental data (Fig. 2).

\section{Results}

The results of the simulations providing information on the thermal residual stresses remaining in the crown after the cooling process are shown in Fig. 5. Stresses were analyzed in terms of their radial (r), vertical (z), shear (rz) and hoop (phi) components due to axial symmetry of the problem. Tensile stresses are mostly developed in the metallic core while the porcelain remains under moderate compressive stresses. Fig. 6 shows a plot of the maximum stresses registered for the three crown configurations. The maximum radial stresses were $280 \mathrm{MPa}$, for the sharp transition; $253 \mathrm{MPa}$ for the crown with $50 \mathrm{M}$ interlayer and $222 \mathrm{MPa}$ for the crown with the

a

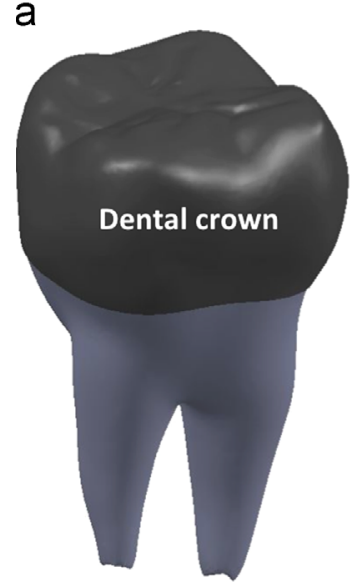

b

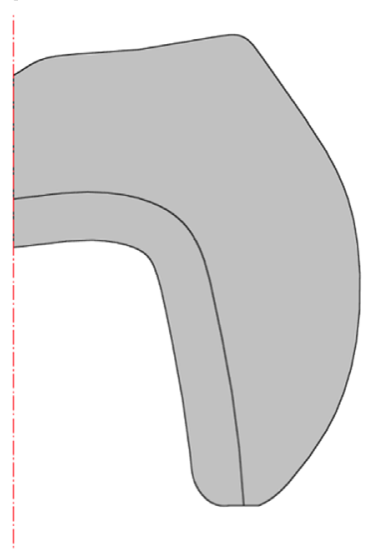

gradated interlayer. The highest radial stresses (tensile) were localized in the top part of the metallic core. Regarding the vertical stresses, the highest tensile stresses were registered in the lateral side of the metallic crown. The sharp transition configuration exhibited $179 \mathrm{MPa}$ of maximum tensile stress and the $50 \mathrm{M}$ interlayer and gradated interlayer configurations yielded $175 \mathrm{MPa}$ and $163 \mathrm{MPa}$, respectively.

In terms of hoop stresses, they were also maximum and positive in the metallic core, following the same trend of the radial and vertical stresses analyzed before. Their magnitude was $289 \mathrm{MPa}$, $259 \mathrm{MPa}$ and $222 \mathrm{MPa}$, for sharp transition, 50M interlayer and gradated interlayer crown configurations, respectively.

High shear stresses were found within porcelain and they were localized mainly at the vicinities of the convex part of the metallic core. Their highest values were $81 \mathrm{MPa}, 66 \mathrm{MPa}$ and $60 \mathrm{MPa}$ for sharp transition, 50M interlayer and gradated interlayer crown configurations, respectively.

Fig. 7 illustrates the spatial variation of the elastic thermal stresses (radial, vertical, shear and hoop), across the metalceramic transition zone of a bilayered (sharp transition) and a trilayered (50M interlayer and gradated interlayer) dental crown. The measurements were made through a straight line across the crown profile where maximum stress values for each stress component were observed (Fig. 5).

It can be seen that the FGM structure results in the least residual stresses and the sharp transition in the highest. It was also noticed that the residual stress levels decerase with an increasing number of layers. Regardless of the number of layers, the stresses reverses in sign, alternating tensile and compressive stresses in the different layers.

\section{Discussion}

The results of the simulations providing information on the thermal residual stresses remaining in the specimens after cooling from high temperature processing are shown in Fig. 5 for crowns with three types of interface configurations: sharp transition, 50M composite interlayer and the gradated interlayer. It must be highlighted at this point that all models had identical

c

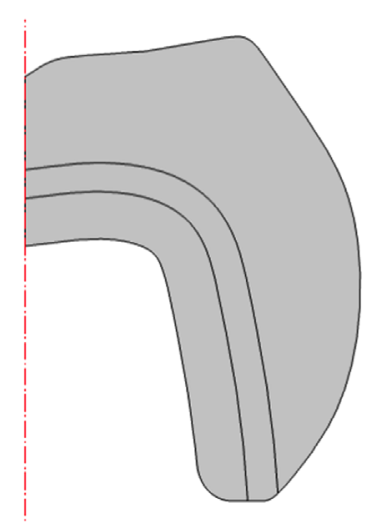

d

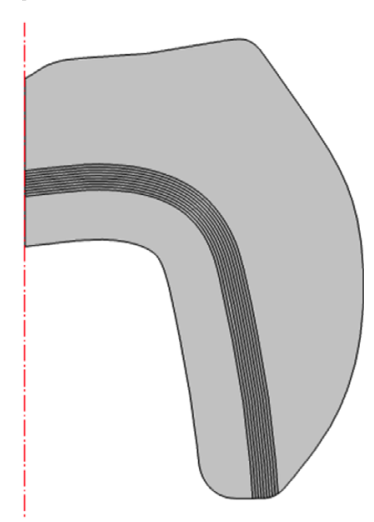

Fig. 3 - Models of the crown with different metal-ceramic interface configurations: (a) original 3D tooth model with the crown selected in dark gray; (b) 2D-axisymmetric model of the crown with sharp transition; (c) 2D-axisymmetric model of the crown with the 50M interlayer, (d) 2D-axisymmetric model of the crown with gradated interlayer. 


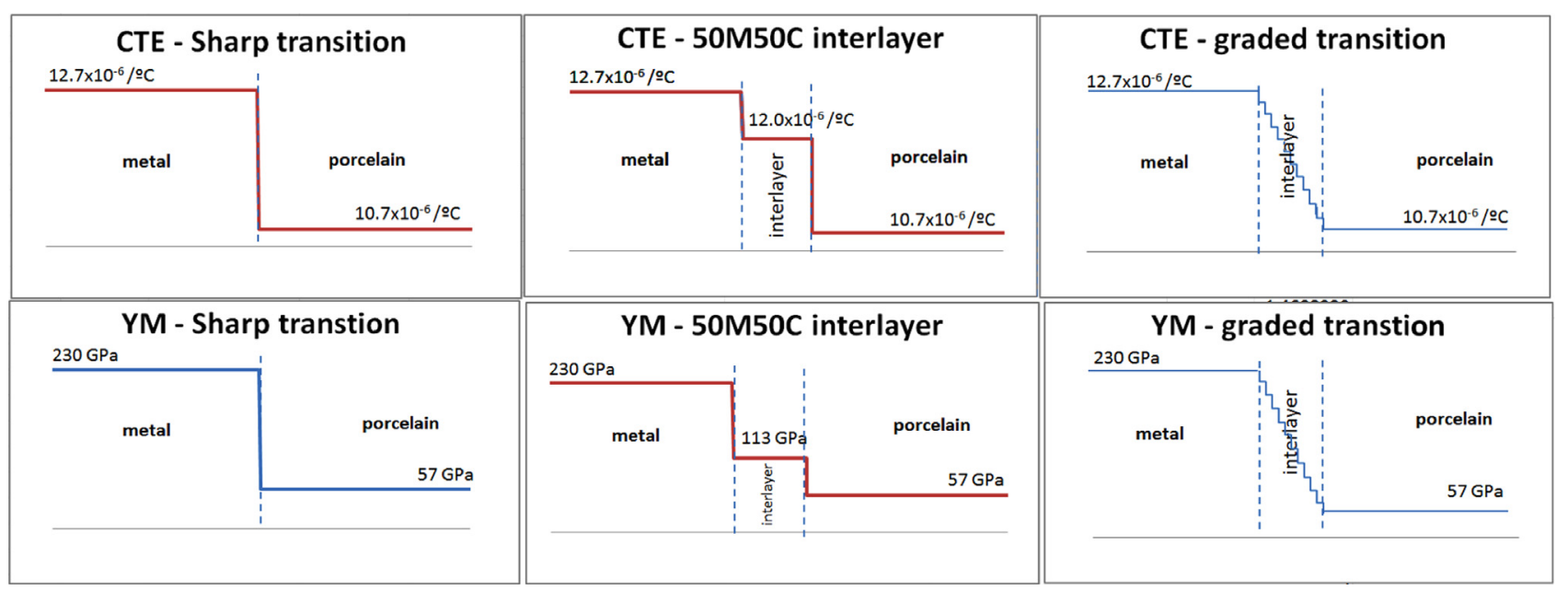

Fig. 4 - Evolution of the coefficient of thermal expansion (CTE) and Young's moduli (YM) across the metal-ceramic interfaces for the different configurations studied.

nominally dimensions and the only difference between them was the interface design. The crown with sharp interface (abrupt interface between the metal and the ceramic) exhibited the highest stress values while that with a gradated interface exhibited the lowest, for all types of stress components analyzed. The stresses found in the crown with the $50 \mathrm{M}$ interlayer exhibited intermediate stress values. Hence, a reduction of $\sim 21 \%$ in maximum radial stresses was observed in the crown with gradated interface relative to that with a sharp interface. The crowns with the $50 \mathrm{M}$ interlayer yield a stress reduction of $\sim 10 \%$. Regarding the maximum vertical stresses, the stress reduction relative to the sharp transition configuration was $2 \%$ and $8 \%$ for the crowns with the $50 \mathrm{M}$ interlayer and the gradated interlayer, respectively. The crown with the gradated interlayer also showed significantly lower shear and hoop stresses, $25 \%$ and $23 \%$ respectively. The $50 \mathrm{M}$ interlayer allowed a stress reduction of $19 \%$ in shear stresses and $10 \%$ of hoop stresses. The stress reduction by using gradated (FGM) architectures was also reported by Huang et al. (2007) for prosthetic systems. They reported $\sim 30 \%$ reduction in maximum principal stresses, originated by contact induced deformations, when functionally gradated layers (FGM architecture) between the crown materials and the joins that attach them to dentin were applied. Huang et al. (2007) and Niu et al. (2009) have also shown that the functionally gradated architectures, aiming at mimicking the functionally gradated structures of the dentin-enamel-junctions (DEJ) in natural teeth exhibited higher critical loads resistance over a wide range of loading rates.

Fig. 5 and 7 show the highest tensile stresses being localized at the near-interface region of the metallic substrate. Zhang et al. (2010) reported similar stress distribution for zirconia and alumina substrates. Thermal residual stresses can have a critical impact in the clinical performance of dental crowns. Hence, tensile stresses located at the veneering porcelain can lead to failure when high occlusal forces are superimposed. Moderate compressive stresses are beneficial to ceramics, while excessive ones can be detrimental to the clinical performance of the restorations.

The results plotted in Fig. 7 show clear differences in the stress distribution and magnitude of stress components analyzed in the different crown models. It shows the stress distribution in a location where higher stress values of each stress component were registered, by the end of the cooling process. The stress distribution profile at this location show clear benefits of FGM design vs. sharp and composite designs. The employment of 9 layers was intended to approach a linearly gradated structure transition. Using the gradated interlayer promoting a gradated transition through 9 layers, resulted in the elimination of the abrupt change in sign of the stress at the interface and in the reduction of the magnitude of thermal stress inside the crown, relative to the conventional sharp interface. The employment of the $50 \mathrm{M}$ interlayer also showed to produce a similar effect, although in a lower extent. The reduction in stress magnitude was achieved and the abrupt change in the sign of the stress at the interface (alternating tensile and compressive stresses) was replaced by two smaller abrupt changes. The alternating stresses can lead to delamination at the interface between metal and ceramic (or between the several composite layers) when a good bonding between the materials is not verifyed. Relative to this point, and concerning the base materials and composites involved in this study, good bond strengths were resported elsewhere based on experiemental works (Henriques et al. 2012a, 2012b, 2012c, 2012d, 2013). Ravichandran (1995) also noticed a decrease in the residual stress levels with an increasing number of layers, which is in accordance to results obtained in this study.

The production of FGMs comprising several layers with different compositions promoting a gradated transition can be made by several available powder metallurgy processes: spray deposition, tape casting, hot pressing and sintering, among others. Ravichandran (1995) demonstrated that the residual stress state employing a gradated transition with 11 layers was comparable to that of a linearly gradated structure.

From the technical point of view, the production a crown with a $50 \mathrm{M}$ composite interlayer between the metal and ceramic is a simpler process than the production of a gradated interlayer. Results have shown that, despite the gradated interlayer had displayed the best stress distribution profiles among the three models simulated in this study, the crown with the $50 \mathrm{M}$ interlayer may also introduce a significant improvement in the 

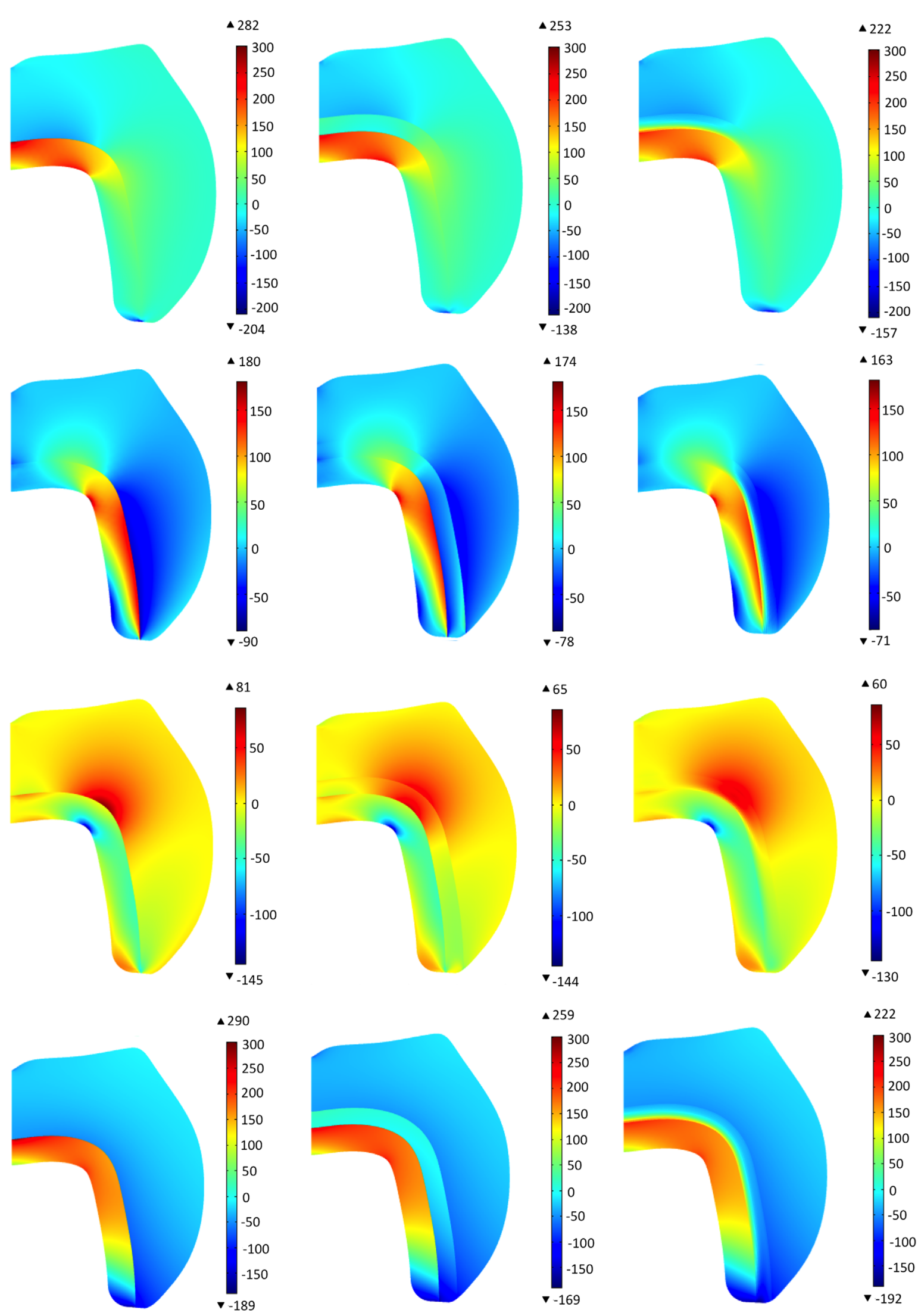

Fig.5 - Radial (r), vertical (z), shear (rz) and hoop (phi) components of the thermal residual stresses [MPa] for different crown designs: (a) sharp transition; (b) 50M composite interlayer; (c) FGM interlayer. 
clinical long tern success of the restoration (Henriques et al., 2012b). Therefore, the $50 \mathrm{M}$ interlayer may be seen as a more immediate solution to be employed in the production of dental restorations. Further, the $50 \mathrm{M}$ and gradated configurations,

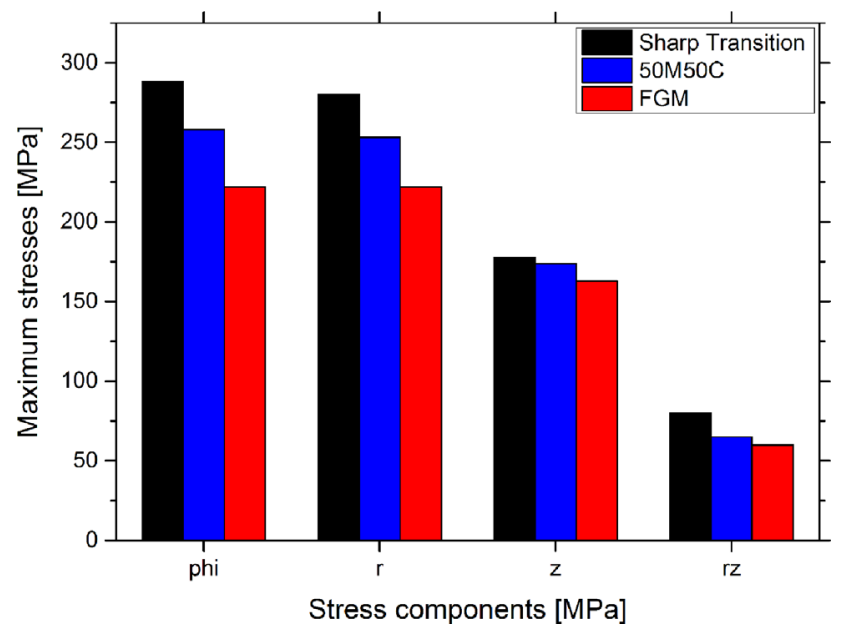

Fig. 6 - Comparative plot of the stress magnitude developed in the dental crown with different interface geometries.
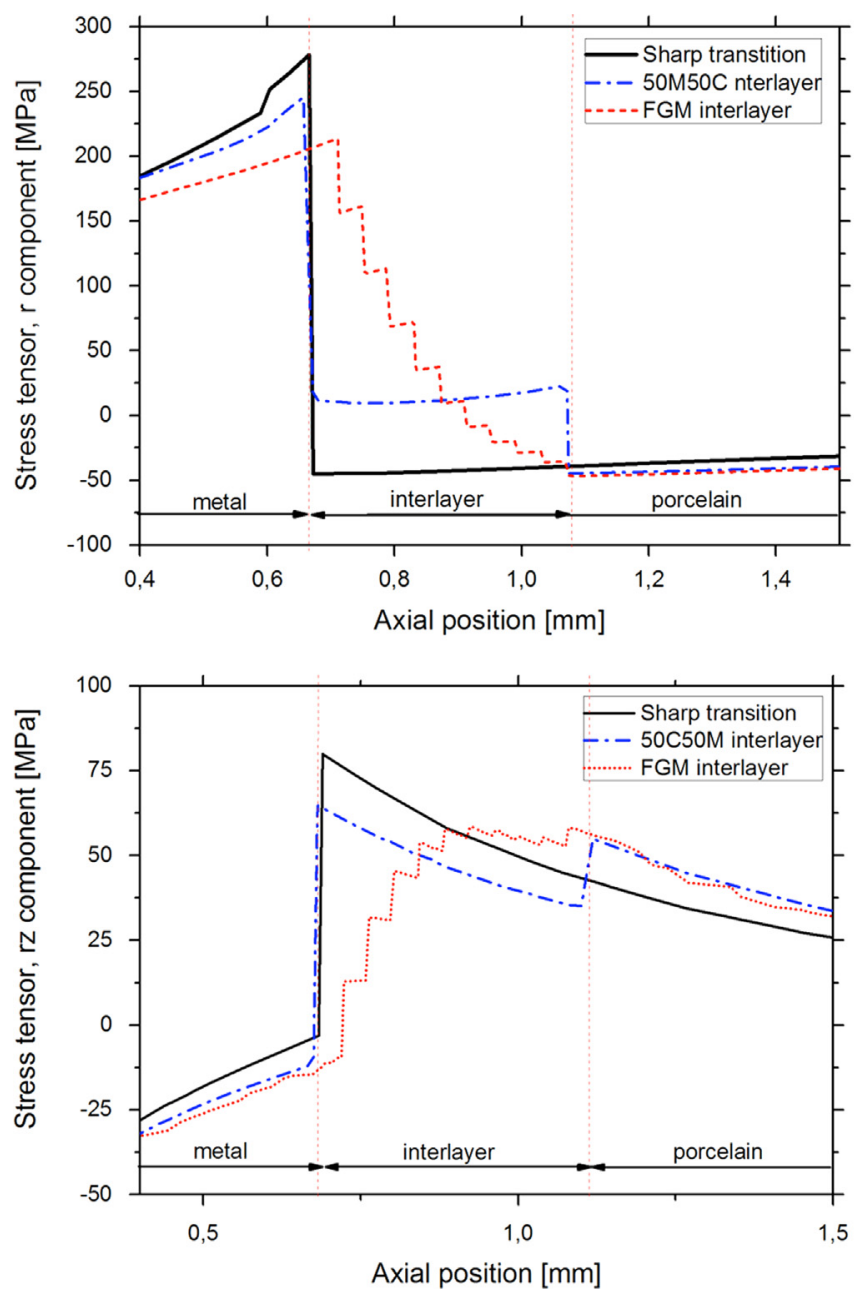

comprising metallic phases embedded in the porcelain, can improve the thermal conductivity, reducing the temperature gradients across the section and hence minimizing the susceptibility to thermal shock-induced fracture.

It should be noted that this study did not account with a hypothetical plastic deformation of the metallic particles from the metal-ceramic composites that compose the crowns with $50 \mathrm{M}$ and the gradated interlayers, which can result in some relaxation of accumulated stresses during cooling from the processing temperature. Some practical aspects, related to the fabrication process, must be therefore considered in the analysis. Porosity or incomplete bonding between ceramic and metal can significantly impact the elastic and thermophysical properties (Hasselman and Johnson, 1987; Tummala and Friedberg, 1970; Pawlowski and Fauchais, 1992), and hence affecting the residual stresses.

\section{Conclusions}

This work includes a study of the thermal residual stresses distributions in dental crowns with different metal-ceramic interface configurations, namely: with a sharp interface (bilayer system); with a 50\% metal-50\% ceramic (50M-50C)
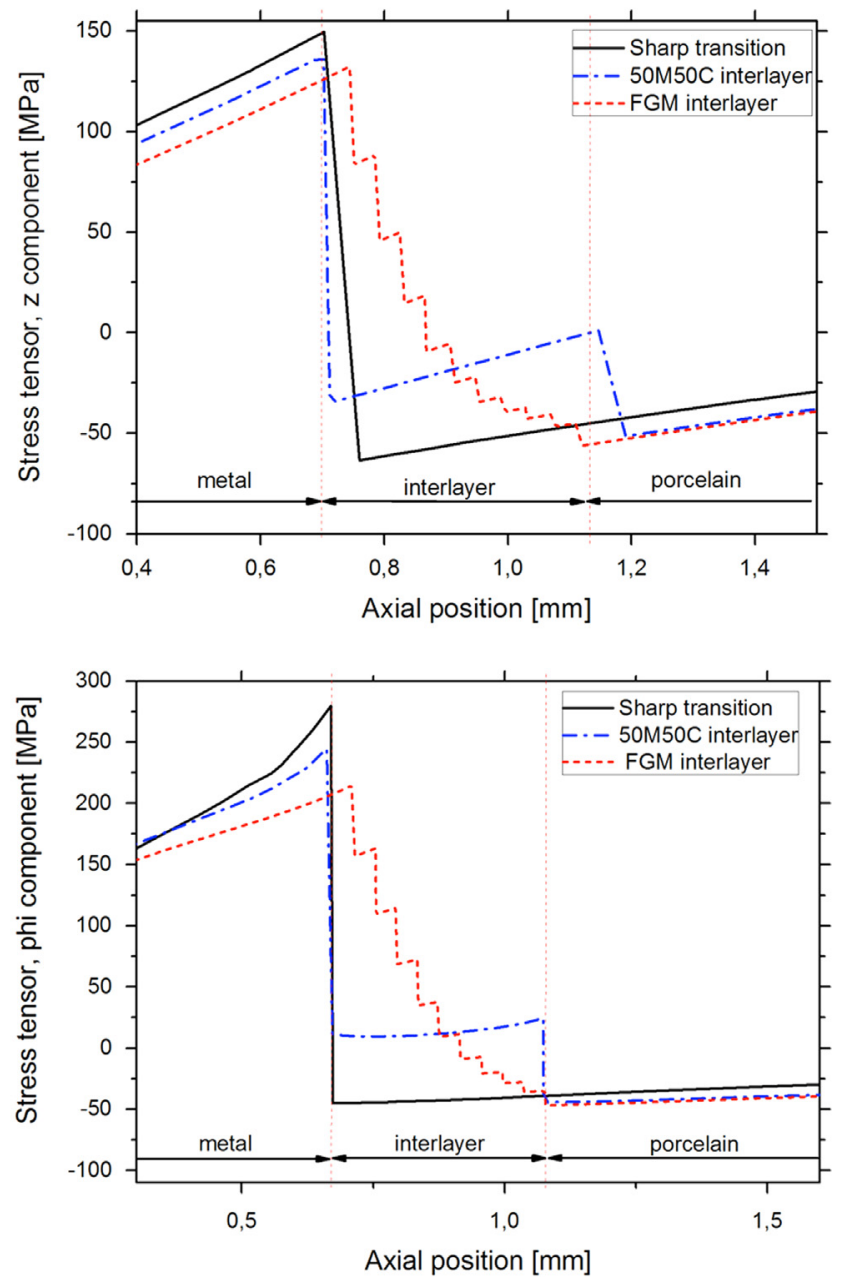

Fig. 7 - Radial (r), vertical (z), shear (rz) and hoop (phi) components of the thermal residual stresses [MPa] measured across the metal-ceramic interface of the different crown configurations. 
interlayer and with a gradated interlayer. These stresses are developed during cooling from porcelain firing temperature. The finite element (FE) simulations, using experimentally determined values of the materials properties, showed that the magnitude of thermal residual stresses on the dental crown can be reduced by over $10 \%$ using a $50 \mathrm{M}-50 \mathrm{C}$ interlayer and by $20 \%$ using a gradated interlayer. The simplified axisymmetric model used in this study has obvious limitations, as it might miss specific components and interactions important in real 3D geometry. Nevertheless, the model indicates the main trends and compares data for different composition profiles and geometries. Improvements in stress distribution profiles were also seen especially in the crown with the gradated interlayer. The benefits of using the $50 \mathrm{M}-$ $50 \mathrm{C}$ interlayer and the gradated interlayer relative to the conventional sharp transition configuration, in terms of thermal residual stresses, shown in this study is expected to positively affect the clinical performance of these restorative systems, especially concerning the fatigue behavior.

\section{Acknowledgments}

The authors acknowledge the Portuguese Foundation for Science and Technology (FCT - SFRH/BPD/87435/2012; EXCL/ EMS-TEC/0460/2012; UID/EEA/04436/2013) for the financial support. Assistance by M.Sc. M. Friman (Aalto University Foundation) in DMA and DIL experiments is also acknowledged.

\section{R E F E R E N C E S}

Anusavice, K.J., 2012. Standardizing failure, success, and survival decisions in clinical studies of ceramic and metal-ceramic fixed dental prostheses. Dent. Mater. 28, 102-111.

Arman, Y., Zor, M., Gungor, M.A., Akan, E., Aksoy, S., 2009. Elasticplastic finite elements analysis of transient and residual stresses in ceramo-metal restorations. J. Biomech. 42, 2104-2110.

Asaoka, K., Tesk, J., 1990. Transient and residual stress in a porcelain-metal strip. J. Dent. Res. 69, 463-469.

Chi, S., Chung, Y., 2003. Cracking in coating-substrate composites with multi-layered and FGM coatings. Eng. Fract. Mech. 70 (10), 1227-1243.

DeHoff, P.H., Barrett, A.A., Lee, R.B., Anusavice, K.J., 2008. Thermal compatibility of dental ceramic systems using cylindrical and spherical geometries. J. Dent. Mater. 24, 744-752.

Fischer, J., Stawarczyk, B., Trottmann, A., Hämmerle, C.H.F., 2009. Impact of thermal properties of veneering ceramics on the fracture load of layered Ce-TZP/A nanocomposite frameworks. Dent. Mater. 25, 326-330.

Gasik, M., 1998. Micromechanical modeling of functionally gradated materials. Comput. Mater. Sci. 13, 42-55.

Gasik, M., Kawasaki, A., Kang, Y., 2005. Optimization of FGM TBC and their thermal cycling stability. Mater. Sci. Forum 492, 9-14.

Hasselman, D.P.H., Johnson, L.F., 1987. Effective thermal conductivity of composites with interfacial thermal barrier resistance. J. Compos. Mater. 21, 508-515.

Henriques, B., Soares, D., Silva, F., 2011. Optimization of bond strength between gold alloy and porcelain through a composite interlayer obtained by powder metallurgy. Mater. Sci. Eng. A 528, 1415-1420.

Henriques, B., Gasik, M., Soares, D., Silva, F., 2012a. Experimental evaluation of the bond strength between a CoCrMo dental alloy and porcelain through a composite metal-ceramic graded transition interlayer. J. Mech. Behav. Biomed. Mater. 13, 206-214.

Henriques, B., Felix, S., Soares, D., Silva, F., 2012b. Shear bond strength comparison between conventional porcelain fused to metal and new functionally graded dental restorations after thermal-mechanical cycling. J. Mech. Behav. Biomed. Mater. 13, 194-205.

Henriques, B., Soares, D., Silva, F., 2012c. Microstructure, hardness, corrosion resistance and porcelain shear bond strength comparison between cast and hot pressed CoCrMo alloy for metal-ceramic dental restorations. J. Mech. Behav. Biomed. Mater. 12, 83-92.

Henriques, B., Soares, D., Silva, F., 2012d. Influence of preoxidation cycle on the bond strength of CoCrMo-porcelain dental composites. Mater. Sci. Eng. C 32 (8), 2374-2380.

Henriques, B., Soares, D., Silva, F., 2013. Hot Pressing effect on the bond strength of a CoCrMoSi alloy to a dental porcelain. Mater. Sci. Eng. C 33 (1), 557-563.

Huang, M., Wang, R., Thompson, V., Rekow, D., Soboyejo, W.O., 2007. Bioinspired design of dental multilayers. J. Mater. Sci.: Mater. Med. 18, 57-64.

Niu, X., Rahbar, N., Farias, S., Soboyejo, W., 2009. Bio-inspired design of dental multilayers: experiments and model. J. Mech. Behav. Biomed. Mater. 2, 596-602.

Özcan, M., 2003. Fracture reasons in ceramic-fused-to metal restorations. J. Oral. Rehabil. 30, 265-269.

Pawlowski, L., Fauchais, P., 1992. Thermal transport properties of thermally sprayed coatings. Int. Metall. Rev. 37, 271-289.

Ravichandran, K.S., 1995. Thermal residual stresses in a functionally graded materials system. Mater. Sci. Eng. A201, 269-276.

Swain, M.V., 2009. Unstable cracking (chipping) of veneering porcelain on all-ceramic dental crowns and fixed partial dentures. Acta Biomater. 5, 1668-1677.

Suresh, S., 2001. Graded materials for resistance to contact deformation and damage. Science 292, 2447-2451.

Taskonak, B., Mecholsky, J.J., Jr., Anusavice, K.J., 2005. Residual stresses in bilayer dental ceramics. Biomaterials 263, 235-3241.

Taskonak, B., Borges, G.A., Mecholsky, J.J., 2008. The effects of viscoelastic parameters on residual stress development in a zirconia/glass bilayer dental ceramic. Dent. Mater. 24, 1149-1155.

Tummala, R.R., Friedberg, A.L., 1970. Thermal expansion of composites as affected by the matrix. J. Am. Ceram. Soc. 53, 376-380.

Yesil, Z.D., Karaoglanoglu, S., Akyll, M.S., Seven, N., 2009. Evaluation of the bond strength of different bonding agents to porcelain and metal alloy. Int. J. Adhes. Adhes. 29, 32-35.

Zhang, Y., Kim, J.W., 2009. Graded structures for damage resistant and aesthetic all-ceramic restorations. Dent. Mater. 25, 781-790.

Zhang, Z., Zhou, S., Li, Q., Li, W., Swain, M., 2010. , Residual stresses in fabrication of core veneered ceramic prostheses. Adv. Mater. Res. 97-101, 2241-2244.

Zhang, Z., Zhou, S., Li, Q., Li, W., Swain, M., 2012. Sensitivity analysis of Bi-layered ceramic dental restorations. Dent. Mater., e6-e14. 